\title{
Accelerator and Ion Beam Tradeoffs for Studies of Warm Dense Matter
}

J. J. Barnard, R. J. Briggs, D. A. Callahan, R. C. Davidson, A. Friedman, L. Grisham, E. P. Lee, R. W. Lee, B. G. Logan, C. L. Olson, D. V. Rose, P. Santhanam, A. M. Sessler, J. W. Staples, M. Tabak, D. R. Welch, J. S. Wurtele, S. S. Yu

May 17, 2005

Particle Accelerator Conference 2005 Knoxville, TN, United States May 16, 2005 through May 20, 2005 
This document was prepared as an account of work sponsored by an agency of the United States Government. Neither the United States Government nor the University of California nor any of their employees, makes any warranty, express or implied, or assumes any legal liability or responsibility for the accuracy, completeness, or usefulness of any information, apparatus, product, or process disclosed, or represents that its use would not infringe privately owned rights. Reference herein to any specific commercial product, process, or service by trade name, trademark, manufacturer, or otherwise, does not necessarily constitute or imply its endorsement, recommendation, or favoring by the United States Government or the University of California. The views and opinions of authors expressed herein do not necessarily state or reflect those of the United States Government or the University of California, and shall not be used for advertising or product endorsement purposes. 


\section{ACCELERATOR AND ION BEAM TRADEOFFS FOR STUDIES OF WARM DENSE MATTER*}

J. J. Barnard ${ }^{1}$, R. J. Briggs 5 , D.A. Callahan ${ }^{1}$, R.C. Davidson ${ }^{3}$, A. Friedman ${ }^{1}$, L. Grisham ${ }^{3}$, E. P. Lee ${ }^{2}$, R. W. Lee ${ }^{1}$, B. G. Logan ${ }^{2}$, C. L. Olson ${ }^{6}$, D. V. Rose ${ }^{4}$, P. Santhanam ${ }^{2}$, A. M. Sessler ${ }^{2}$, J. W. Staples ${ }^{2}$, M. Tabak ${ }^{1}$, D. R. Welch ${ }^{4}$, J. S. Wurtele ${ }^{2}$, S. S. Yu ${ }^{2}$

\section{Lawrence Livermore National Laboratory 2. Lawrence Berkeley National Laboratory 3. Princeton Plasma Physics Laboratory 4. Mission Research Corporation 5. Science Applications International Corporation \\ 6. Sandia National Laboratory}

\section{Abstract}

One approach for heating a target to "Warm Dense Matter" conditions (similar, for example, to the interiors of giant planets or certain stages in Inertial Confinement Fusion targets), is to use intense ion beams as the heating source (see refs.[6] and [7] and references therein for motivation and accelerator concepts). By consideration of ion beam phase space constraints, both at the injector, and at the final focus, and consideration of simple equations of state and relations for ion stopping, approximate conditions at a target foil may be calculated. Thus target temperature and pressure may be calculated as a function of ion mass, ion energy, pulse duration, velocity tilt, and other accelerator parameters. We connect some of these basic parameters to help search the extensive parameter space (including ion mass, ion energy, total charge in beam pulse, beam emittance, target thickness and density.

\section{Ion Stopping:}

We first examine $d E / d X$, where $E$ is the ion energy and $X$ $\equiv \int \rho d z$ is the integrated range of the ion (cf, ref. [1]).

For heating solid aluminum (at room temperature) over a range of ion mass from 4 amu (Helium) to 126 amu (Iodine), the energy loss at the peak of the $d E / d X$ curve $\left(d E / d X_{\max }\right)$ may be parameterized approximately as: $\left(1 / Z^{2}\right) d E / d X_{\max } \approx 1.09\left(\mathrm{MeVcm}^{2} / \mathrm{mg}\right) A^{-0.82}$

where $Z$ and $A$ are the ion nuclear charge and atomic mass, respectively. Expressing $d E / d X_{\max }$ as a function of $A$ only yields:

$d E / d X_{\max } \approx 0.35\left(\mathrm{MeVcm}^{2} / \mathrm{mg}\right) A^{1.07}$.

Thus, the peak energy loss rate increases (nearly linearly) with ion atomic mass.

Similarly, the energy at the peak increases with ion nearly quadratically with $A$ :

$$
E\left(\text { at } d E / d X_{\max }\right) \approx 0.052 \mathrm{MeV} A^{1.803} .
$$

Target uniformity is another important consideration. In ref. [2] it was pointed out that target temperature uniformity can be maximized in simple planar targets if the particle energy reaches the maximum in the energy loss rate $d E / d X$ when the particle has reached the center of the foil (see figure 1). For any specified fractional deviation in target temperature (assuming the energy is deposited in a time short so that no hydrodynamic, radiative, or other cooling has occurred) one can determine the energy at which the ion must enter and exit the foil. From the $d E / d X$ curves of ref. [1] we find that for the entrance energy to have less than a $5 \%$ lower energy loss rate relative to the peak in $d E / d X, \Delta E / E \approx 1.0$, where $\Delta E$ is the difference in ion energy between entering and exiting the foil, and $E$ is the energy at which $d E / d X$ is maximum. The spatial width of the foil $Z$, for a $5 \%$ temperature non-uniformity is then given by:

$Z=\Delta E /(\rho d E / d X) \approx 0.77 \mu \quad A^{0.733}\left(\rho_{a l} / \rho\right)$

Here we have used $\rho_{\mathrm{al}}=2.7 \mathrm{~g} / \mathrm{cm}^{3}$ to convert the range into a physical distance. So by using materials of low density such as metallic foams, for example, the width of the foil can be relatively large, which allows longer heating times and accesses interesting densities.

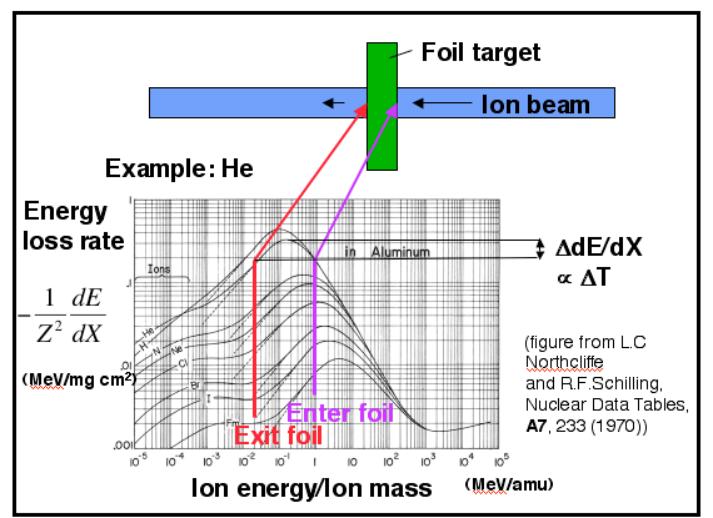

Figure 1. Temperature variations in an ion-beam heated foil can be minimized by choosing an ion and energy such that the peak in $\mathrm{dE} / \mathrm{dX}$ occurs in the center of the foil (ref. [2]).

\section{Hydrodynamic disassembly time and target temperature:}

The sound speed $c_{s}$ is given by $c_{s}=(\gamma P / \rho)^{1 / 2}=(\gamma[\gamma-$ $1] U / \rho)^{1 / 2}$. For an instaneously heated target a rarefaction wave propagates inward at $\sim c_{\mathrm{s}}$ while matter flows outward at $\sim 2 \quad c_{\mathrm{s}}$ (for a1D gas) (ref. [3]). Thus, for meaurement of material properties, heating needs to occur on a time scale such that the rarefaction wave does not reach to within some minimum diagnosable spatial scale over the duration of the pulse.

In order to calculate more accurately the sound speed and the temperature achieved in the heating, one needs to understand the relation between energy density and ionization state $Z^{*}$. As a first estimate, we use a model 
developed by Zeldovich and Raizer and summarized in ref. [4]. A second model for equation of state uses the Thomas Fermi model for calculating the distribution of electrons within an atom (see ref. [5], and reference therein for a description).

\section{Examples of accelerator requirements:}

Using the scaling described in the previous section for ion beam stopping, the time scale for hydrodynamic expansion and the equation of state we are able to make estimates of the required beam parameters for exploring the Warm Dense Matter regime. Table 1 gives examples of requirements for a, $\mathrm{Neon}^{+1}(A=20.17)$ at foil entrance energy $\left(E_{\max }\right)$ of $19 \mathrm{MeV}$, The energy at the center of the foil $\left(E_{\text {center }}\right)$ and the energy at the exit of the foil $\left(E_{\text {min }}\right)$ are listed in the captions to the tables. Three different mass densities of Aluminum target are given: Solid density (2.7 $\mathrm{g} / \mathrm{cm}^{3}$ ) and $10 \%$ and $1 \%$ of solid, which can be produced by making an aluminum "foam." In turn for each target density, three target temperatures are shown. The table is based on a minimum diagnosable length scale $Z_{\min }$ of 40 $\mu$. It is clear from the table that solid density, although resulting in the highest energy density, requires vary short pulse durations, because the foil width is smaller than $Z_{\text {min }}$ and so only a small rarefaction wave propagation distance is allowed. But for the $1 \%$ and $10 \%$ cases, the foil is larger than $Z_{\min }$, so that the rarefaction wave propagation distance can be 10's or 100's of microns, with concomitantly longer pulse duration times. In all cases the plasma temperature is in the few to tens of $\mathrm{eV}$, and the required number of particles is in the order of $10^{12}$ to $10^{13}$ particles, for equivalent focal spot radii of $1 \mathrm{~mm}$.

\begin{tabular}{|c|c|c|c|c|c|c|c|c|c|}
\hline$\rho\left(\mathrm{g} / \mathrm{cm}^{3}\right)(\%$ solid $)$ & \multicolumn{3}{|c|}{$0.027(1 \%)$} & \multicolumn{3}{|c|}{$0.27(10 \%)$} & \multicolumn{3}{|c|}{$2.7(100 \%)$} \\
\hline Foil length $(\boldsymbol{\mu})$ & \multicolumn{3}{|c|}{480} & \multicolumn{3}{|c|}{48} & \multicolumn{3}{|c|}{4.8} \\
\hline$k T(e V)$ & 3.1 & 4.8 & 15 & 4.2 & 7.3 & 18 & 5.9 & 12 & 22 \\
\hline $\mathrm{Z}^{*}$ & 1.1 & 2.1 & 2.7 & 0.56 & 1.7 & 2.6 & 0.56 & 1.2 & 2.5 \\
\hline$\Gamma_{i=}=Z^{* 2} e^{2} n_{i}^{1 / 3} / k$ & 0.45 & 1.1 & 0.95 & 0.30 & 0.63 & 1.4 & 0.30 & 0.70 & 1.6 \\
\hline $\begin{array}{l}\mathrm{N}_{\text {wows }} /\left(\mathrm{r}_{\text {spot }} / 1 \mathrm{~mm}\right)^{2} \\
/ 10^{12}\end{array}$ & 1 & 3 & 10 & 1 & 3 & 10 & 1 & 3 & 10 \\
\hline$\Delta t(\mathrm{~ns})$ & 84 & 48 & 27 & 3.8 & 2.2 & 1.2 & 0.04 & 0.03 & .014 \\
\hline $\mathrm{U}\left(\mathrm{J} / \mathrm{m}^{3}\right) / 10^{11}$ & .015 & .045 & 0.15 & 0.15 & 0.45 & 1.5 & 1.5 & 4.5 & 15 \\
\hline
\end{tabular}

Table 1. Neon beam: $Z=10, A=20.17, E_{\min }=7.7 \mathrm{MeV}$, $E_{\text {center }}=12.1 \mathrm{MeV}, E_{\max }=20.1 \mathrm{MeV}$, and $\Delta \mathrm{z}_{\min }=40 \mu$.

Table 2 lists the requirements for various ion species to produce a $10 \mathrm{eV}$ target temperature in a $10 \%$ solid density aluminum foam.

\begin{tabular}{|c|c|c|c|c|c|c|c|c|c|c|}
\hline $\begin{array}{c}\text { Beam } \\
\text { Ion }\end{array}$ & Z & [amu] & $\begin{array}{c}\text { Energy at } \\
\text { Bragg Peak }\end{array}$ & $\begin{array}{c}\text { dEldX at } \\
\text { Bragg Peak } \\
\text { (HeY-cm } 2 \text { l } \\
\text { mg) }\end{array}$ & \begin{tabular}{|l|} 
Foil Entrance \\
Energy [app]
\end{tabular} & $\begin{array}{c}\text { Delta } z \text { for } \\
5 \% \text { T variation } \\
\text { [10\% solid A] } \\
\text { [microns] }\end{array}$ & $\begin{array}{c}\text { Beam Energy } \\
\text { for } 10 \mathrm{er}\end{array}$ & $\begin{array}{c}\text { t_hydro= } \\
\text { delta zl[ } 2 \mathrm{cs}] \\
\text { at } 10 \mathrm{er} \\
\text { [ns] }\end{array}$ & $\begin{array}{c}\text { Beam Power } \\
\text { persq. mm } \\
\text { [GW/mm2] }\end{array}$ & $\begin{array}{l}\text { Beam current } \\
\text { for } 1 \mathrm{~mm} \\
\text { diameter spot } \\
\text { (A] }\end{array}$ \\
\hline$\overline{L i}$ & $\overline{3}$ & 6.94 & 1.6 & 2.68 & 2.4 & 22.1 & 3.3 & 0.5 & 6.1 & 1990.6 \\
\hline $\mathbf{N a}$ & 11 & 22.99 & 15.9 & 11 & 23.9 & 53.5 & 8.0 & 1.3 & 6.1 & 200.3 \\
\hline K & 19 & 39.10 & 45.6 & 18.6 & 68.4 & 90.8 & 13.6 & 2.2 & 6.1 & 69.8 \\
\hline Rb & 37 & 85.47 & 158.0 & 39.1 & 237.0 & 149.7 & 22.4 & 3.7 & 6.1 & 20.2 \\
\hline $\mathrm{Cs}$ & 55 & 132.91 & 304.0 & 59.2 & 456.0 & 190.2 & 28.5 & 4.7 & 6.1 & 10.5 \\
\hline
\end{tabular}

$r_{\text {spot }}^{2}=2 \varepsilon f \Delta v_{\text {spread }} / \mathrm{v}$

Table 2. Parameters for five different ion beam species such the central temperature of a $10 \%$ solid density Aluminum foil reaches $10 \mathrm{eV}$.

\section{Final focus Requirements:}

In this paper we consider the case where beam plasma neutralizes both a drift compression region and the final focus. We may make simple estimates for the contribution to the spot size from chromatic effects (i.e. for the effects of a velocity spread) from a particular optical systems. Here we choose a "thick" solenoidal lens in which a beam enters a solenoid with zero convergence angle and focuses to a spot within the solenoid, it can be shown to have a radius from emittance and chromatic effects $r_{\text {spot }}$ to be given approximately by:

$r_{\text {spot }}^{2} \approx\left(\pi r_{0} / 2\right)^{2}\left(\Delta v_{\text {spread }} / \nu\right)^{2}+\left(2 \varepsilon_{x} f / \pi r_{0}\right)^{2}$

where $r_{0}$ is the radius of the beam at the entrance to the solenoid, $f$ is the focal length, i.e., the distance from the entrance of the solenoid to the focal spot, and $\varepsilon$ is the beam emittance. Here $r_{\text {spot }}$ and $r_{0}$ are the beam radii(= $\left.2^{1 / 2}\left\langle r^{2}\right\rangle^{1 / 2}\right)$ at the focal spot and entrance to the solenoid respectively, and $\left.\varepsilon_{\mathrm{x}} \equiv 4\left(\left\langle x^{2}\right\rangle\left\langle x^{\prime 2}\right\rangle-\left\langle x x^{\prime}\right\rangle^{2}\right)^{1 / 2}\right)$ is the unnormalized emittance. The quantity $r_{\text {spot }}$ is minimum when $r_{0}^{2}=(2 / \pi) \varepsilon f /\left(\Delta v_{\text {spread }} / v\right)$ and has the value
At minimum pulse duration a velocity "tilt" is converted to a velocity spread, so achieving high beam intensity will limit the velocity tilt.

It is apparent from equation (10) that a large velocity spread has deleterious effects in the focusing. Thus a larger velocity tilt will allow a shorter pulse but will yield a large overall spot. But if the longitudinal emittance is small, a larger velocity tilt is not needed to achieve the short pulse duration. Thus to obtain a small spot there are tradeoffs that can be made between longitudinal and transverse emittance, which might made if one is easier to obtain than the other. This may be made more explicit by expressing equation (10) in terms of the transverse and longitudinal normalized emittances:

$r_{\text {spot }}^{2}=4 \varepsilon_{n x x} \varepsilon_{n z} f /\left(3^{1 / 2} \beta^{3} c \Delta t\right)$

Here $\varepsilon_{n x}$ is the normalized $x$ emittance $\left(=4 \beta\left(\left\langle x^{2}\right\rangle\left\langle x^{\prime 2}\right\rangle\right.\right.$ $\left.\left.\left\langle x x^{\prime}\right\rangle^{2}\right)^{1 / 2}\right)$ and $\varepsilon_{n z}$ is the normalized $z$ (longitudinal) emittance (defined here as $\left.=3 \beta\left(\left\langle z^{2}\right\rangle\left\langle z^{\prime 2}\right\rangle-\left\langle z z^{\prime}\right\rangle^{2}\right)^{1 / 2}\right), f$ is the final focal length, $\beta$ is the final velocity in units of $\mathrm{c}$ and $\Delta t$ is the final pulse duration. Prime indicates derivative with respect to the path length $s$, and non-relativistic velocities are assumed. Table 3 lists a number of parameters for possible $23 \mathrm{MeV} \mathrm{Na}$ beams, with final pulse duration $\Delta t$ of $1 \mathrm{~ns}$, total charge of $0.1 \mu \mathrm{C}$, and final 
spot radius of $1 \mathrm{~mm}$. The table illustrates some of the tradeoffs that can be made involving pulse duration before drift compression, velocity tilt and requirements on longitudinal and transverse emittance.

\begin{tabular}{|c|c|c|c|c|c|c|c|c|}
\hline Pulse & Velocity & Maximum & Maximum & Maximum & Beam radius & Neutralized & Maximum & \\
\hline duration & tilt & Ims velocity & emittance & normalized & at solenoid & Drift length & Ims velocity & Normalized \\
\hline (before drift & (Head to tail) & spread & unnormalized & emittance & entrance & & spread & Long. Emittance \\
\hline compression) & dv/v_tilt & dp/p_rms & $4 \mathrm{rms}$ & $4 \mathrm{rms}$ & Ro & & dp/p_rms & (mm-mrad) \\
\hline (ns) & & (befor drift comp) & (mm-mrad) & (mm-mrad) & (m) & (m) & (at injector) & \\
\hline 20 & 0.05 & $7.22 \mathrm{E}-04$ & 49.5 & 2.3 & 0.031 & 5.34 & $1.98 \mathrm{E}-03$ & 8.2 \\
\hline 20 & 0.1 & $1.44 E-03$ & 24.7 & 1.2 & 0.016 & 2.67 & $3.97 E-03$ & 16.5 \\
\hline 20 & 0.2 & $2.89 E-03$ & 12.4 & 0.6 & 0.008 & 1.34 & $7.93 \mathrm{E}-03$ & 32.9 \\
\hline 50 & 0.05 & $2.89 \mathrm{E}-04$ & 49.5 & 2.3 & 0.031 & 13.77 & $1.98 \mathrm{E}-03$ & 8.2 \\
\hline 50 & 0.1 & $5.77 E-04$ & 24.7 & 1.2 & 0.016 & 6.89 & $3.97 E-03$ & 16.5 \\
\hline 50 & 0.2 & $1.15 \mathrm{E}-03$ & 12.4 & 0.6 & 0.008 & 3.44 & $7.93 \mathrm{E}-03$ & 32.9 \\
\hline 100 & 0.05 & $1.44 \mathrm{E}-04$ & 49.5 & 2.3 & 0.031 & 27.83 & $1.98 \mathrm{E}-03$ & 8.2 \\
\hline 100 & 0.1 & $2.89 E-04$ & 24.7 & 1.2 & 0.016 & 13.91 & $3.97 E-03$ & 16.5 \\
\hline 100 & 0.2 & $5.77 E-04$ & 12.4 & 0.6 & 0.008 & 6.96 & $7.93 \mathrm{E}-03$ & 32.9 \\
\hline 250 & 0.05 & 5.77E-05 & 49.5 & 2.3 & 0.031 & 69.99 & $1.98 \mathrm{E}-03$ & 8.2 \\
\hline 250 & 0.1 & $1.15 E-04$ & 24.7 & 1.2 & 0.016 & 35.00 & $3.97 E-03$ & 16.5 \\
\hline 250 & 0.2 & $2.31 E-04$ & 12.4 & 0.6 & 0.008 & 17.50 & $7.93 E-03$ & 32.9 \\
\hline 250 & 1 & $1.15 E-03$ & 2.5 & 0.1 & 0.002 & 3.50 & $3.97 E-02$ & 164.6 \\
\hline
\end{tabular}

Table 3. Comparison of requirements on a $23 \mathrm{MeV}$ Na beam with final pulse duration of $1 \mathrm{~ns}$, and final focal spot radius of $1 \mathrm{~mm}$, assuming neutralized drift compression and solenoidal final focus (with a $15 \mathrm{~T}$ field corresponding to a $0.7 \mathrm{~m}$ focal length), satisfying equations (9) and (11). The injected beam has energy $1 \mathrm{MeV}$ and pulse duration $171 \mathrm{~ns}$.

We may use the ion stopping equations, together with injector and final focus equations to examine the overall target performance as a function of ion energy, mass and other parameters.

At the injector end, the normalized emittance may (ideally) be related to the temperature $T_{\mathrm{s}}$ and radius $r_{\mathrm{b}}$ of the source:

$\varepsilon_{\mathrm{N}}=2 r_{b}\left(k T_{\mathrm{s}} / m c^{2}\right)^{1 / 2}$

$=0.051 \mathrm{~mm}-\operatorname{mrad}\left(r_{\mathrm{b}} / 0.25 \mathrm{~cm}\right)(20.1 / A)^{1 / 2}\left(k T_{\mathrm{s}} / 2 \mathrm{eV}\right)^{1 / 2}$

Even if the injector emittance is dominated by optical aberrations an effective temperature may be used in eq. (12). To avoid voltage breakdown, the diode gap distance $d$ must be sufficiently large:

$d=.01 \mathrm{~m}\left(V_{\mathrm{d}} / 100 \mathrm{kV}\right)^{2}$ if $d>1 \mathrm{~cm}$

Since we are considering large currents $(d>1 \mathrm{~cm})$ is appropriate. We may combine eqs. (12) and (13) to obtain:

$\varepsilon_{\mathrm{f}}=22.4 \mathrm{~mm}-\mathrm{mrad}(4 / \Delta)\left(k T_{s} / 2 \mathrm{eV}\right)\left(V_{d} / 400 \mathrm{kV}\right)^{2}$

$\times\left(12 \mathrm{MeV} / q V_{f}\right)^{1 / 2}$

The Child Langmuir current

$I=\left(4 \pi \varepsilon_{0} / 9\right)(2 q / m)^{1 / 2}\left(V_{d}^{3 / 2} / \Delta^{2}\right)$

$=0.6 A(20 / A / q)^{1 / 2}(4 / \Delta)^{2}\left(V_{d} / 400 k V\right)^{3 / 2}$

Here $\Delta=d / r_{\mathrm{b}}$ which is usually in the range $2.5-8$ to minimize non-linearities. Here we choose 4 as a typical nominal value.

The total charge $I \Delta t$ may be written

$I \Delta t=0.12 \mu C(20 / \mathrm{A} / q)^{1 / 2}(4 / \Delta)^{2}\left(V_{d} / 400 k V\right)^{3 / 2}\left(\Delta \mathrm{t}_{\mathrm{d}} / 200 \mathrm{~ns}\right)$

The pulse energy $\mathrm{E}_{\text {pulse }}$ may be written:

\section{References}

[1] I.C. Northcliffe and R. F. Schilling, "Range and Stopping Power Tables for Heavy Ions," Nuclear Data Tables, A7 233-463 (1970).

[2] L. R. Grisham, Moderate Energy Ions for High Energy Density Physics Experiments, Physics of Plasmas, 11, 5727 (2004).

[3] L.D. Landau and E.M. Lifshitz, Fluid Mechanics, [Pergamon Press, Oxford], Chapter 10, Section 92, problem 2. (1959).

[4] R. J. Harrach and F.J. Rogers, J. Appl. Phys. 52, 5592 (1981).
$E_{\text {pulse }}=V_{f} I \Delta t=$

$=2.8 \mathrm{~J}(20 / \mathrm{A} / \mathrm{q})^{1 / 2}(4 / \Delta)^{2}\left(V_{\mathrm{d}} / 100 \mathrm{kV}\right)^{3 / 2}\left(\Delta \mathrm{t}_{\mathrm{d}} / 200 \mathrm{~ns}\right)\left(V_{\mathrm{f}} / 20 \mathrm{MV}\right)$

Equations (14) through (16) describe the phase space and pulse energy obtainable from an injector. The final target energy density $U$ can be calculated from the total pulse energy

$U=2 V_{f} I \Delta t /\left(3 \pi r_{\text {spot }}^{2} \Delta z\right)$

and the target temperature can be expressed as:

$k T_{\text {targ }} \approx 2 U A_{\text {targ }} \mathrm{m}_{\text {amu }} /\left(3\left(Z^{*}+1\right) \rho\right)$

$=3 \mathrm{eV}\left(\mathrm{A}_{\mathrm{targ}} / 27\right)\left(3 /\left(\mathrm{Z}^{*}+1\right)\right)\left(2 \mathrm{eV} / k T_{\mathrm{s}}\right)^{1 / 2}$

$\times\left(0.05 / \Delta v / \mathrm{v}_{\text {tilt }}\right)(q / 1)^{0.32}(4 / \Delta)\left(\Delta t_{\mathrm{d}} / 200 \mathrm{~ns}\right)$

$\times\left(V_{\mathrm{d}} / 400 \mathrm{kV}\right)^{-1 / 2}\left(V_{\mathrm{f}} / 20 \mathrm{MV}\right)^{0.815}(0.7 \mathrm{~m} / f)$

As discussed before, the target temperature in eq. (19) can be achieved if the pulse duration is sufficiently small compared to the hydro time. The pulse duration at the target $\Delta t_{\mathrm{t}}$ can be expressed as:

$$
\begin{aligned}
\Delta t_{\mathrm{t}} & =2 \mathrm{~A} \mathrm{~m} \mathrm{~m}_{\mathrm{amu}} \mathrm{c} \varepsilon_{\mathrm{nz}} /\left(\mathrm{q} \mathrm{V}_{\mathrm{f}} \Delta \mathrm{v} / \mathrm{v}_{\text {tilt }}\right) \\
& =1 \mathrm{~ns}\left(\varepsilon_{\mathrm{nz}} / 8 \mathrm{~mm}-\mathrm{mrad}\right)\left(20 \mathrm{MeV} / \mathrm{V}_{\mathrm{f}}\right)(\mathrm{A} / \mathrm{q} / 20)\left(0.05 / \Delta \mathrm{v} / \mathrm{v}_{\text {till }}\right)
\end{aligned}
$$

where $\Delta v / v \_t i l t$ is the head-to-tail tilt imposed on the beam during final drift compression.

The equations above may be useful in evaluating concepts for accelerator-drivenWDM. 